\title{
A instância corpórea do humano: Sexualidades e subjectividades, mulheres e ética
}

The Bodily Nature of the Human: Sexualities and Subjectivities, Women and Ethics

L'instance corporelle de l'humain : sexualités et subjectivités, femmes et éthique

Isabel Allegro de Magalhães

\section{CpenEdition}

\section{Journals}

\section{Edição electrónica}

URL: http://journals.openedition.org/rccs/3740

DOI: $10.4000 /$ rccs.3740

ISSN: 2182-7435

\section{Editora}

Centro de Estudos Sociais da Universidade de Coimbra

Edição impressa

Data de publição: 1 junho 2010

Paginação: 111-125

ISSN: 0254-1106

\section{Refêrencia eletrónica}

Isabel Allegro de Magalhães, «A instância corpórea do humano: Sexualidades e subjectividades,

mulheres e ética », Revista Crítica de Ciências Sociais [Online], 89 | 2010, posto online no dia 01 outubro 2012, consultado o 14 novembro 2019. URL : http://journals.openedition.org/rccs/3740 ; DOI :

$10.4000 /$ rccs. 3740

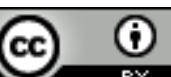




\title{
ISABEL ALLEGRO DE MAGALHÃES
}

\section{A instância corpórea do humano: Sexualidades e subjectividades, mulheres e ética}

\begin{abstract}
Este texto reflecte sobre as principais etapas da evolução do pensamento feminista quanto à questão da diferença e da identidade sexual, desde as primeiras levas dos feminismos anglo-americanos e franceses, à pulverização de agrupamentos sociais e teóricos de mulheres nos EUA (lesbian, black e gay studies na década de 1980; teoria queer da década seguinte; novos materialismos dos anos 2000). Será que a diferença sexual é apenas um resíduo da construção histórico-cultural que o pensamento patriarcal fez das mulheres e do feminino? Ao retomarem a estrutura corpórea do sujeito, as novas correntes neomaterialistas obrigam a repensar a diferença sexual em ligação com novas modalidades de articulação com o não-humano, o mundo animal, as biotecnologias, a tecnociência e a biosfera. Talvez as mulheres possam formar, se assim o quiserem, uma energia singular, que articule fisiologia e simbolização, e contribuir com uma resposta sua à perplexidade do mundo, trazendo uma dimensão, agora simbólica e eticamente operante, da maternidade.
\end{abstract}

Palavras-chave: corpo; feminismo; identidade sexual; igualdade e diferença; novos materialismos; subjectividades.

I am rooted, but I flow.

VIRGINIA WOOLF

1. Num breve (e necessariamente simplificado) apanhado histórico quanto ao lugar que a instância corpórea ocupa (ou não) no pensamento de diferentes movimentos e grupos feministas, torna-se clara a diversidade de perspectivas que ora conferem ora retiram relevo e significação ao corpo de mulheres e de homens. Negando ou afirmando a instância "corpo", enquanto elemento matricial na construção pessoal e social de subjectividades e identidades, cada uma dessas perspectivas contém, de algum modo, um propósito político e ético, que se manifesta quer na afirmação da igualdade quer na de diferença sexual, em propostas de indiferenciação sexual como em posicionamentos de instabilidade ou de permanente metamorfose. 
Interessa-me aqui reflectir sobre as questões que algumas dessas posições levantam, porque algumas delas - levadas cada uma às suas extremas consequências - quase eliminam de cena o conjunto humano mulheres, enquanto conjunto específico. É que, uma vez eliminadas quaisquer diferenças entre os sexos (para além daquelas que cultural e socialmente herdámos e que todos pretendemos rasurar), acabará por não ter sentido falar de homens e de mulheres, mas tão só de "humanos" (a não ser no que toca à morfologia dos corpos e à procriação, mesmo que só in vitro). Do mesmo modo, uma vez atingido esse patamar de total igualdade ou de indiferenciação construída, os movimentos de mulheres perderiam a sua razão de ser. Tal como falar de subjectividades sexuadas e dos contributos diferenciados das mulheres e dos homens à vida do mundo deixaria de ter qualquer sentido.

Vejamos então como se alinham alguns desses posicionamentos, para depois formular algumas interrogações.

2. Historicamente, a consciência feminista partiu do exterior para o interior, no sentido em que os primeiros movimentos e tomadas de posição das mulheres se preocuparam sobretudo com o exercício de uma cidadania plena, por parte das mulheres, tendo ficado para mais tarde a preocupação relativa a questões de diferença ou de identidade sexual. A reflexão começou por fazer-se sobre a secundarização das mulheres ao longo da História, resultante de uma definição do sexo feminino formulada por homens. O objectivo primeiro foi garantir direitos fundamentais às mulheres, reivindicando a igualdade entre os sexos, depois dita "paridade".

Assim, o corpo, enquanto instância da subjectividade, é praticamente inexistente nos feminismos anglo-americanos até à década de 1980. Quando mencionado, o corpo é tido sobretudo como "território" sobre o qual as mulheres têm direitos, nomeadamente na importante questão do aborto, em que se exerce uma decisão inalienável das mulheres. Esse contexto não levou a equacionar a questão da diferença empírica dos corpos como matriz de outra diferenciação. A ausência de referências à instância corpórea torna-a quase só um "acidente", na medida em que ela é considerada como não interferente na fundação do sujeito e no exercício da subjectividade.

Simone de Beauvoir, por exemplo, defendeu a igualdade entre os sexos, inscrevendo-a filosoficamente sob o regime do universal, isto é, assente nos ideais republicanos da "fraternidade" (não esquecer que frater é masculino) e do "Homem". E o Iluminismo francês valorizou a noção abstracta de "Homem" para usá-lo enquanto metafísica do universal, "fundante" dos direitos humanos e da cultura moderna (Kristeva, 2005: 210). Contudo, qualquer visão universalista, ao anular singularidades, corre o 
risco de empobrecer o real, neste caso tomando o masculino como totalidade. E se as reivindicações desta matriz feminista se situam ideologicamente contra o patriarcalismo e o falogocentrismo ocidentais, nem por isso deixam de buscar um lugar dentro do sistema, não pondo por isso em causa nem o sistema nem a sua visão unilateral (porque só masculina) do humano, isto é, não implicam o pensamento a nível ontológico. Daí que corpo, e com ele a diferença sexual, se apaguem ou diluam nesse UM, o Homem, dito universal, ocultando assim a existência de outro modo de subjectividade, a das mulheres, também ela, naturalmente, plural. No entanto, há no universalismo uma justeza ética a ressaltar, que reside na reclamação de direitos e de oportunidades iguais para todos os humanos, homens ou mulheres.

A unanimidade interna na posição dessas feministas anglo-americanas, sobretudo a partir do final dos anos 70 , irá desmembrar-se, devido à experiência expressa por parte de muitas mulheres que, não sendo brancas, heterossexuais e de classe média, mas negras, lésbicas e de outras classes sociais, se sentiram excluídas do movimento feminista. Surgem assim os black, gay, lesbian studies, entre outros, provocando com isso uma cisão que pôs em causa a força inicialmente convergente da luta das mulheres. Rapidamente surgem estudos, obras, antologias, que espelham essa fragmentação. A vontade de identificações mais plurais leva àquilo que designam como separatismos, do que dão conta, por exemplo nos black studies, o manifesto de feminismo negro: "A Black Feminist Statement", produzido na segunda metade dos anos setenta em Boston pelo colectivo "The Combahee River Collective"; e ainda as posições de Patricia H. Collins (1990; 2000). No seu conjunto, as "black theories" fazem sempre sobressair uma espiritualidade e laços comunitários de matriz africana, decorrentes de modos específicos de solidariedade, expressos na sabedoria UBUNTU, fortemente contrastante com o individualismo ocidental. Também do feminismo lésbico e sua intenção separatista surge uma diversidade de títulos, de que é exemplar a antologia For Lesbians Only: A Separatist Anthology, dos anos 1980, congregadora de textos também da década anterior, e ainda uma diversidade de revistas, surgidas em vários países.

3. Outra corrente do feminismo será a que surge, a partir dos anos 1970, em França, onde o contributo de mulheres com formação filosófica, literária, linguística, psicanalítica (Luce Irigaray, Hélène Cixous, Catherine Clément e Julia Kristeva, entre tantas outras) irá pôr o acento noutros elementos. O feminismo francês virá então pensar o modo como as subjectividades se constituem, concebendo-as sempre a partir de corpos sexuados. 
Isto de par com a luta cívica, sociopolítica, pela igualdade de oportunidades, só que articulando sempre a luta das mulheres com uma mudança de paradigma social, ou seja, propondo uma mudança claramente revolucionária dos modelos de vida. Relativamente a estas posições, o feminismo anglo-saxónico construir-se-á em diferendo (cf. Stanton, 1980), embora algumas das feministas norte-americanas a dada altura a ele se tenham aliado, entre as quais Elaine Showalter, Susan Bordo, Ann Rosalind Jones, Biddy Martin. Posições idênticas à francesa irão sendo formuladas noutros contextos culturais, por exemplo, em Itália, na Índia, no Brasil, em alguns países de África.

Considerando que a História foi apagando o corpo das mulheres, reduzindo-o à sua representação - literária, artística e filosófica - operada por homens (cf. Grosz, 1999), as feministas francesas expressam a consciência de que com o corpo das mulheres também a subjectividade feminina, naturalmente plural, fora eliminada, o que uso de "Homem" para designar o conjunto dos humanos exemplifica. Nesta perspectiva, a noção de igualdade é pelas feministas francesas desvirtuada em nome de uma nova diferença, já não concebida como "desvio" da norma masculina. Trata-se de um pensamento de certa forma materialista, fora já do binómio homem/mulher, e que parte do existente: o corpo. A instância corpórea passa então a ser considerada como um dos fulcros fundadores das subjectividades e seus exercícios. Por exemplo, com Luce Irigaray as feministas francesas reconhecem que

[p]ensar a partir do homem como UM não é ainda pensar. [...]; a espécie humana não pode elaborar uma civilização sem se preocupar em representar validamente os dois sexos que a integram [...] e não é possível neutralizar a diferença homem/mulher em nome de uma igualdade fictícia. (Irigaray, 1992: 74, 79, 75) ${ }^{1}$

Esta convicção antropológica e filosófica levará algumas feministas, designadamente francesas, italianas, indianas, a buscar elementos para uma reflexão sobre o carácter sexuado das subjectividades, especificamente, da subjectividade feminina. A pesquisa incidirá nos gestos de simbolização do corpo, da experiência corpórea e do desejo, materializados nos seus lugares de inscrição: lugares discursivos, textuais e artísticos, verbais e não-verbais. O corpo sexuado será então descoberto como eixo do exercício de qualquer subjectividade e a consciência - transcendida, embora, dizia

\footnotetext{
${ }^{1}$ Esta e todas as outras traduções são da minha responsabilidade, salvo quando haja indicação em contrário.
} 
Merleau-Ponty e também Sartre ${ }^{2}$ - será entendida na sua "incarnação corporal": corpo e consciência, ambos situados em contextos culturais diversos e com eles interagindo. A linha subjacente a esta pesquisa não pergunta pelas diferenças entre os sexos, mas pelo modo como as diferenças surgem de corpos distintos, ${ }^{3}$ o que à partida parece afastar qualquer essencialismo. Trata-se de uma visão em certo sentido "materialista", pelo facto de fazer do sexo uma das matrizes das múltiplas formas de se ser e estar. É interessante que na visão de Adrienne Rich o corpo seja dito como a geografia mais próxima do sujeito, como instância através da qual este diz eu, e como modo do desejo.

Ora a escrita, enquanto criação artística, ao simbolizar a experiência corpórea e o desejo, é lugar de acesso à subjectividade, neste caso, de mulheres, que nunca é um dado estável; pelo contrário, está sempre em metamorfose, assumindo formas tão diversas quanto cada pessoa. Por isso, a categoria "feminino" ou a "feminitude", a existir, não é concebida como estável e homogénea, mas como princípio nuclear de diferenciação, fluido e gerador de multiplicidades. Nesta perspectiva, o apelo ético é o do reconhecimento das diferenças: diferenças sexuadas que haverá que reconhecer, situando-as em plano de igualdade ou, dito de outra forma, reconhecimento da igualdade de estatuto entre todas as diferenças.

4. Na década de 1990, de dentro mas ao arrepio de algumas perspectivas teóricas gay e lésbicas, outra linha de discurso sobre as identidades sexuais surge no panorama destas reflexões: a da teoria queer (Butler, 1990; Sedgewick, 1990; De Lauretis, 1991). Trata-se de um quadro teórico-crítico desconstrutivista e subversivo nas ciências sociais (e também noutras áreas), que vem abalar categorias e a linguagem nos estudos sobre sexualidade, subjectividade, gender e identidades. $\mathrm{Na}$ análise crítica de discursos, literários ou outros, a mobilidade e a descentração que esta perspectiva propõe tornaram-se claramente operantes. Contudo, a meu ver, no caso da percepção das identidades sexuadas, aparece-me como limitativa.

Uma das convicções queer é a de que a distinção homem/mulher a nível psicológico só se sustenta devido ao factor repetitivo da performatividade 4 típico das sociedades patriarcais. Insiste-se em que os "fantasmas

\footnotetext{
${ }^{2}$ Ver Maurice Merleau-Ponty, Phénoménologie de la perception (1945) e Jean-Paul Sartre, L'Être et le néant (1943).

3 É Claire Colebrook quem o afirma, no seu livro sobre Deleuze (Gilles Deleuze. London/N.Y.: Routledge, 2002), citado por Rosi Braidotti (2006).

${ }^{4}$ Butler, 1990: 33. Cf. ainda "Changing the subject", in The Judith Butler Reader, 334. Esta ideia quanto à performatividade é em parte herança hegeliana, da Fenomenologia do Espírito.
} 
[assim designados] ontologicamente consolidados 'homem' e 'mulher' são meros efeitos encenados, que se tornaram fundamentos da medida normativa do real", 5 sem na realidade o serem (cf. Butler, 1991: 21). Tal afirmação, contudo, não impede que pensemos a possibilidade de alterar esses actos repetitivos que modelam o real, de modo a iniciar outros que renovem esse modelo herdado. Aliás, a própria Judith Butler parece entrar em contradição: por um lado, quando afirma que as normas culturais limitam o agente: "O que está em jogo são normas culturais que, na situação, condicionam e limitam o agente"; 6 por outro lado, quando sugere que o sujeito pode mudar essas normas através do seu próprio comportamento: "Eu realizo essa renovação [das normas culturais] pela repetição dos meus próprios actos". 7 A contradição residirá nesta convicção de que também há performatividades transformadoras.

Convencida de que as "categorias sexuais [estabelecidas] não dão conta da plasticidade erótica", 8 Judith Butler (2004: 113) propõe que cada sujeito assuma alternadamente identidades diversas, fora de qualquer pólo estável (o que denota alguma presença de Foucault). Desse modo, a seu ver, as matrizes sexuadas deveriam ser anuladas e as categorias identitárias suspensas, já que o próprio acto de nomear, de dizer homem/mulher, homo- ou heterossexual, é, só por si, violento: "a própria nomeação estabelece imediatamente uma delimitação [...]" (Butler, 1994: 8).

O que está aqui em causa não é tanto uma irrelevância do corpo, mas a sua capacidade de assumir representações que excedam as tradicionais "divisões binárias" (homem/mulher, feminino/masculino, homo-/hetero-) (Martin, 1994: 11-112). Essa será uma forma de tornar essas categorias estruturas temporalmente renováveis (Butler, 2004: 333). Mesmo assim, o corpo parece ser aqui deixado entre parênteses, com um cariz neutro ou plástico e transformável, sem ter de identificar-se com nenhum dos sexos, deixando por isso o sujeito livre para assumir o sexo e o gender que bem entender. A teoria queer chega assim a fazer a apologia de uma alternância de identidades no mesmo sujeito, sejam elas paródicas ou pastiches, mas em qualquer caso errantes e fora das "normas" sociais estabelecidas.

Com esta indiferenciação das categorias sexuais e a fuga aos habituais binarismos sexuais pretende evitar-se a hegemonia heterossexual nas

\footnotetext{
5 Butler, "Imitation and gender insubordination", in Diana Fuss (org.). Inside/Out: Lesbian Theories, Gay Theories. New York: Routledge, 1991, 21. Apud Isaiah Green, 2002: 525.

6 "What are being performed are cultural norms that condition and limit the actor in the situation" (Butler, 2004: 345).

7 "I perform [...] that renewal in the repeated acts of my person" (Butler, 2004: 334).

${ }^{8}$ Cf. Green, 2002: 524.

9 "the naming is at once the setting of the boundary $[\ldots]$ ".
} 
sociedades actuais (Salih, 2004: 10). Ora há aqui um explícito propósito ético que visa fazer da indistinção identitária uma estratégia política que impeça a segregação social daqueles que são classificados como sexualmente marginais, abrindo condições para o acolhimento do outro, seja ele quem for e como for, com quem quer que viva. A questão da diferença entre feminino e masculino é, porém, a meu ver, diferente, anterior e autónoma à da orientação sexual. Esta será apenas um dos modos possíveis de "homens" ou "mulheres" viverem a sexualidade, sem que isso altere a diferença sexual dos corpos e a vida sexuada e sexual. Por isso, não parece possível pensar em identidade sexual quando se fala da orientação sexual (homo-, hetero-), porque nem hetero- nem homosexualidades estão desligadas de corpos concretos, isto é: a orientação sexual não rasura o corpo, naturalmente sexuado. Ora Butler reconhece-o (Butler, 2004: 28) e, ao considerar o corpo natural ou pré-cultural inexistente, faz equivaler sexo e gender, afirmando que o primeiro, tal como o segundo, é uma construção social e cultural. Aliás, a própria noção de heterossexualidade é entendida como não-natural, também ela um construto sociocultural.

Claro que no ser humano não há já "natureza”, uma vez que esta está desde logo histórico-culturalmente construída pela simbolização. Contudo, o corpo, como dado empírico, será sempre o lugar a partir de onde se simboliza. Assim não sendo, e no contexto queer, surge a suspeita de o sexo ser alienável por vontade do sujeito, como se este pudesse escolher "des-encorporadamente" qualquer gender. E, de facto, a política queer, anti-identitária (mas só por táctica social, percebe-se), propõe que se fale de "gente" ou "pessoas", à partida assexuadas ${ }^{10}$ de modo a ninguém poder ser discriminado pela sua orientação sexual classificada como desviante.

(Entre parêntesis, é interessante ter presente que, do lado da sociologia, várias são as vozes que desde o início de 2000 contestam as perspectivas queer. Entre elas, as de Esther Newton, Bob Connell, Adam Isaiah Green. Green (2002) chega até a apontar uma nova etapa que designa já como postqueer. Critica na posição queer o facto de se assumir um sujeito "irreal", à margem da ordem social, bem como a sobrevalorização da diferença straight/gay, contra a qual argumenta que "nem tudo o que é gay é queer e subversivo, bem como nem tudo o que é heterossexual é dominante e hegemónico". Além disso, essa crítica postqueer denuncia a total desconstrução das identidades sexuais, dando por certo que gays e lésbicas preferirão não identificar a sua orientação sexual. Mas Green faz notar que isso

10 Bordo, 1990: 152. Cf. Amaral, 1995: 22. 
conduziria à sua exclusão dos estudos sobre a sexualidade, citando vários estudos de caso realizados em comunidades gay e lésbicas em Nova Iorque, que mostram o contrário: que o assumir da orientação sexual lésbica ou gay é exactamente a razão de uma liberdade experienciada. Observa ainda Green que tais estudos revelam grande diversidade interna (clivagens sociais entre grupos, maior ou menor identificação com modelos sociais masculinos e femininos, posições políticas ou religiosas - "gay republicans", "gays for Christ"). Por isso, tais estudos manifestam o grande potencial subversivo desses grupos, na sua capacidade de resistência e no seu poder de negociação relativamente às categorias sociais instituídas. Green não esclarece, porém, se entende as categorias sociais, que considera chave, como estáticas ou em devir, em processo de metamorfose.)

Voltando à teoria queer: o que nela está em causa, a nível social, é uma suspensão aparentemente temporária das categorias sexuais, por elas circunscreverem socialmente as identidades, tornando as escolhas ditas "não-normalizadas" assimétricas em relação ao regime heterossexual vigente. E ao descentrar a instância "sujeito", fazendo vacilar todos os conceitos identitários, a perspectiva queer aposta no potencial político subversivo e emancipatório que a nível sociopolítico (e não só) é capaz de gerar.

5. Nos anos 2000, com os chamados neomaterialismos, outras questões surgem. Estas novas correntes retomam a estrutura corpórea do sujeito para a repensarem em novos contextos. Os contextos são, entre outros, os das biotecnologias e das tecnociências (cf. Pearson, 1997); são também os das novas modalidades de ligação ao não-humano, ao mundo animal, à biosfera. (É importante não esquecer o quanto, no início dos anos 1990, os ecofeminismos contribuíram para uma consciência da profunda ligação e interdependência entre humanos e natureza $\left.{ }^{11}\right)$.

O facto de hoje estarem tecnicamente disponíveis novas possibilidades, algumas das quais perigosas por transgredirem fronteiras nunca antes transgredidas, levanta problemas novos. Recorrendo em parte à ampla lista de casos citados por Braidotti, cito alguns exemplos de diferentes níveis dessa actual transgressão de limites. Por exemplo, as formas de simulação da realidade: nos call-centres e seus "proletários digitais"; nos chat-rooms. Também os biopoderes fornecidos pela engenharia genética que domestica a Natureza com direitos de autor (as patentes) e que permite procriação sem sexo; clonagens; os OGMs e outras manipulações de ADN; a criação de interfaces

${ }_{11}$ Ver Gaard (org.), 1993. 
com máquinas inteligentes e as experiências (quase espectrais) da própria vida vivida através de outras vidas, com identidades inventadas, sexo virtual, etc; as próteses electrónicas; as diversas recomposições do corpo; os implantes que alteram a materialidade dos corpos. Tudo isto - observa Judith Halberstam - torna já impossível distinguir "histórica, científica e culturalmente $[\ldots]$ os corpos das suas extensões tecnicamente mediadas" (cf. Braidotti, 2005-2006: \$2612).

Donna Haraway (2004a: 8 ss.) fala da emergência de um bestiário ciborgue capaz de pôr em risco o humano tradicional, perante o qual apresenta a sua figura, por si própria considerada blasfema, do "ciborgue" enquanto mito a simbolizar essa hibridização: "somos ciborgues, híbridos de máquina e organismo, vivemos num mundo ciborgue". Haraway concebe um futuro de "identidades fracturadas", sem medo de afinidades novas entre animais e máquinas e outras hibridizações (Haraway, 2004b: 240 ss.). Por sua vez, e enquanto bióloga, Luciana Parisi (2004) afirmará que o feminino deixou de poder estar relacionado com a identidade comum às mulheres empíricas, dada a interferência hoje detectada de elementos da biologia molecular na questão da diferença sexual. O excesso que as actuais possibilidades, virtuais e já reais, permitem abre para perigos novos que Rosi Braidotti (2005-2006: \$3) formulará do seguinte modo:

A tecnologia está no cerne de um processo de apagamento de distinções de categorias fundamentais entre o eu e o outro; uma espécie de heteroglossia da espécie, uma espantosa hibridização que combina ciborgues, monstros, insectos e máquinas, constituindo uma abordagem fortemente pós-humana daquilo a que antes chamávamos "o sujeito corpóreo". ${ }^{13}$

Rosi Braidotti reconhece que tudo isso nega o corpo como lugar da subjectividade, fazendo dele "um construto técnico-cultural" (Braidotti, 2005-2006: \$20). Trata-se de um paradigma que já nada tem a ver com o quadro antropocêntrico clássico. Neste contexto, Braidotti revê posições que classifica como de um humanismo renovado, a que uma ecofeminista indiana - Vedanta Shiva - chamou "humanismo planetário" (Shiva, 1997), criticando-as em alguns pontos e apreciando-as noutros (Braidotti, 2007: 66). Braidotti expõe alguns dos pontos de vista ecofeministas, aproximando-se de uns e

\footnotetext{
${ }_{12}$ As citações deste texto de Braidotti seguem a sua própria numeração dos parágrafos.

13 "Technology is at the heart of a process of blurring fundamental categorical divides between self and other; a sort of heteroglossia of the species, a colossal hybridisation which combines cyborgs, monsters, insects and machines into a powerfully posthuman approach to what we used to call "the embodied subject".
} 
afastando-se de outros. $\mathrm{O}$ aspecto mais significativo é a não-coincidência que aponta entre o seu próprio ponto de vista não-antropocêntrico e essa espécie de humanização do meio ambiente, proposta pelo ecologismo profundo - em inglês designado por deep ecology -, no qual Braidotti vê resíduos ainda de um individualismo liberal (Braidotti, 2007: 112-115). Muitas destas novas possibilidades, consideradas já "pós-humanas", em geral não são pensadas nem vividas no quadro de uma fronteira ou de um limite de ordem ética. E aí é que surge o problema. Resultam frequentemente de um enfeudamento à economia política do capitalismo biotecnológico, mais que de uma expansão dos possíveis do humano e do não-humano - na linha de pensamento deleuziano, e agora também na de Luciana Parisi que, em Abstract Sex, e centrada nas evoluções moleculares, fala da possibilidade de novas formas de subjectividade transversal (Parisi, 2004). O que é aqui objecto de denúncia é o facto de o leque das escolhas corresponder ao livre exercício de apenas alguns - a comunidade científica -, deixando a maioria à mercê da lógica cultural e acrítica dos consumos. Algumas posições, contudo, distinguem-se das do mainstream, precisamente pela sua preocupação ética em definir alguma noção de limite imperativo, reconhecível por todos.

Donna Haraway (2004a: 8) expressa a necessidade de uma "responsabilidade" pela resistência aos determinismos das tecnociências. Susan Star pretende que seja introduzido no próprio processo dessas ciências aquilo a que chama o ponto de vista do "monstro", que seria o ponto de vista crítico daqueles que "sofrem dos abusos do poder tecnológico", pois esses terão mais elementos para análise. ${ }^{14}$ Levando mais longe essa inquietação, Rosi Braidotti aponta a ausência perversa de critérios éticos, palpável nas "fantasias da omnipotência cibernética que dominam o imaginário popular acerca dos corpos-máquinas de hoje" e as proliferações quantitativas do sujeito (cf. Braidotti, 2002: IV cap., e 2005-2006: \$6). A partir daí, Braidotti retoma Deleuze para apresentar a sua noção de "sujeito nómada" ou rizomático, em constante devir, mas responsável e comprometido, vivendo embora na abertura a múltiplas alianças e pertenças. (É significativa a consonância desta proposta com as de Kristeva [2005: 337]).

É neste contexto que Braidotti revisita a diferença sexual (2007: 182) para valorizar a entidade corpórea do sujeito, na mesma linha de Irigaray, que Deleuze viria depois a ecoar - o que Rosi Braidotti não deixa de sublinhar. Tal valorização vem de par com o relevo que atribui ao elemento zoe, em contraposição ao elemento bios. Este implica o nexo social, político e discursivo,

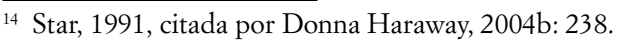


específico dos humanos, ao passo que zoe é um elemento transversal a todas as espécies, vitalista e sexualizado (2007:37; 109-111). Braidotti elogia esse vitalismo antiessencialista de zoe, apontando a sua importância particular em plena era de tecnologias avançadas, e diz:

O que está em causa numa ética sustentável não é o feminino codificado, no código falogocêntrico do imaginário patriarcal, mas o feminino como projecto, como movimento de desestabilização da identidade, e por isso em devir. Chamo a isso o "feminino virtual" e ligo-o ao projecto social e simbólico de redefinição da subjectividade da mulher, levado a cabo pelo feminismo. (Braidotti, 2007: 183 e 184) ${ }^{15}$

Através de tudo isto, Braidotti sai do imaginário de uma transcendência técnica e de um hiperindividualismo generalizado, patente quer nos processos de evasão do corpo quer na acumulação de escolhas gratuitas ou no culto do artifício, para a isso contrapor uma visão, na sequência de Espinosa, qualitativa e assente na afectividade como raiz ética do sujeito (Braidotti, 2005-2006: \$26).

6. Perante tão diversas linhas de pensamento e de preocupação, não me parece possível oferecer quaisquer conclusões. Terminarei aqui, deixando à consideração duas ou três interrogações que me habitam. Num tempo em que presenciamos uma ampliação da consciência da biodiversidade, dos elementos bio e zoe na sua relação com o humano, da coextensividade do corpo com a natureza e com o ambiente (traço este claramente deleuziano, e já mesmo espinosista), pergunto-me se o apagamento da diferença sexual não representará mais uma perda na diversidade humana? Pergunto-me se tal apagamento ou anulação não virá rasurar alguns dos actuais dados das neurociências que têm mostrado o funcionamento corpóreo e sexuado da própria mente, fisicamente localizado no cérebro. Num tempo de metamorfoses identitárias e de consumo de múltiplas hibridizações, em que o virtual se tornou mais forte que o empírico - com "cash flow sem dinheiro, leis naturais sem natureza, feminismos sem mulheres e procriação sem sexo" (Braidotti, 2005-2006: \$4) -, pergunto-me, ainda, e com alguma perplexidade, se o sujeito colectivo "mulheres", uma vez ganha a batalha da igualdade, deixará de poder ser declinado, já que parece tender-se para uma

15 "What is at stake in sustainable ethics is not the feminine as codified in the phallogocentric code of the patriarchal imaginary, but rather the feminine as project, as movement of destabilization of identity and hence of becoming. I call this "the virtual feminine" and I connect it to the social and symbolic project of redefinition of female subjectivity that is undertaken by feminism." 
diluição da diferenciação sexual e, por isso mesmo, de qualquer denominador comum ao conjunto antropológico "mulheres".

No contexto de tal perplexidade, evoco cinco vozes de mulheres: duas delas retiradas de um mito grego (e o mito, enquanto construção simbólica, permite captar um secreto apelo, há muito sedimentado); as outras três nossas contemporâneas. Do mito, vêm as figuras de Perséfone e Deméter, cujo enredo sucintamente relembro:

Perséfone vivia junto a Deméter, deusa da fecundidade da Terra e sua mãe: raptada por Hades, passa a habitar com ele o seu mundo. A sua ausência fará Deméter percorrer todo o universo conhecido, arriscada a desaparecer no abismo. Mas Perséfone grita, e o seu grito faz prova de que está viva. No entanto, enquanto o reencontro não se dá, Deméter abandona o Olimpo e o seu exílio na Terra provocará a esterilidade dos campos, imersos agora num infindável Inverno. Perante a calamidade, Zeus ordena o regresso de Perséfone à mãe, o que já não será possível: o seu amor com Hades estava simbolicamente selado, vinculando-a a ficar com ele. Surge uma proposta de conciliação: Perséfone dividirá o seu tempo entre Hades e Deméter: seis meses com cada um. E esta modalidade de ligação das mulheres trará a ambas uma alegria imensa e à Terra seis meses de fecundidade (no Verão) e seis meses de pousio (no Inverno).

Neste mito, leio uma encenação da capacidade das mulheres para simultaneamente viverem várias pertenças e a existência de um indestrutível laço entre elas, tornado condição de possibilidade do futuro da Terra. Os elementos potencialmente mobilizadores residem aqui, a meu ver, na disposição para conciliar uma liberdade nas opções de vida e uma reinvenção da energia partilhada entre mulheres, enquanto participantes de um outro gender, agora inventado pelas suas próprias vozes, e por isso livre, proteico, multiforme.

Das três vozes contemporâneas chega-nos, curiosamente, um idêntico desafio.

HélèneCixous notava (em 1976) que "Escrever nofemininoé deixar vir o simbólico, ou seja, a voz da mãe, é deixar vir o quehá de mais arcaico” (Cixous, 1992).

Maria de Lourdes Pintasilgo, numa das suas últimas intervenções públicas (em 2004), confessava: "Escolhi não ter filhos, escolhi ser mãe da Terra, gerar, cuidar o futuro". ${ }^{16}$

16 Maria de Lourdes Pintasilgo, Comunicação não-escrita ao "Seminário Evocativo do I Congresso Feminista e da Educação em Portugal” (Lisboa, 2004), aqui citado de memória. 
Julia Kristeva (em 2005) retomará a mesma ideia, repensando "uma maternidade amante" que não fosse mero processo biológico, mas "ternura eficaz", "eros diferido", "desejo expectante" (Kristeva e Clément, 1998: 26, 93).

Embora de forma menos explícita, também Rosi Braidotti (em Transpositions), ao falar da analogia entre mulher, animal, mãe e terra como dimensões importantes para as pós-estruturalistas como para as ecofeministas, defende a activação da dimensão zoe, essa dimensão "animal" ou pré-humana da vida, em oposição à dimensão bios, a dimensão claramente humana, discursiva. E, ao fazê-lo, considera que isso acontece também através da diferença sexual ou da substância que o feminino materno e material produz, enquanto caminho virtual de um devir que conduz para fora, para o exterior do humano. Considera que é assim que se ultrapassa a femininidade clássica e que se transpõe a maternidade patriarcalmente definida, o que significa, diz, "uma metamorfose no sentido de uma mudança de localização e de um lugar activo de transformação [...]" (Braidotti, 2007: 110). ${ }^{17}$

Kierkegaardianamente algo $\mathrm{t}(\mathrm{r})$ emente, pergunto-me agora se as mulheres não poderão escolher formar uma energia singular, a articular fisiologia e simbolização, como sugere Kristeva, ${ }^{18}$ e desse modo constituírem uma resposta no feminino à perplexidade do mundo, enquanto exercício de uma outra maternidade, simbólica e eticamente operante.

Quatro vozes tão diversas quanto unânimes e não apenas entre si como com as suas antepassadas clássicas, Deméter e Perséfone. Todas elas se situam a si mesmas sob o signo da afectividade, falam ou exibem de uma visão aberta e livre, de alianças várias e relações plurais, um afecto acima de tudo disponível para cuidar a vida e manter viva a Terra (Kristeva, 2005: 317;337).

Provisórias e incertas, não será que estas metáforas potenciam o futuro? Não saberia responder. I flow, but I am rooted, I'm rooted, but I flow.

\section{Referências bibliográficas}

Amaral, Ana Luísa (1995), "Emily Dickinson: uma poética de excesso". Dissertação de Doutoramento, Faculdade de Letras da Universidade do Porto.

Barrington, Judith (org.) (1991), An Intimate Wilderness: Lesbian Writers on Sexuality. Portland, OR: Eighth Mountain Press.

Bordo, Susan (1990), "Feminism, Postmodernism, and Gender-Scepticism", in Linda J. Nicholson (org.), Feminism /Postmodernism. New York: Routledge.

17 "This aims to point a way out of the metaphysical quagmire of classical femininity and patriarchally ordained motherhood and to transpose it. This is a metamorphosis in the sense of a shift of location and an active site of transformation of a minority into a 'becoming-minoritarian'”.

${ }^{18}$ Nas próprias palavras de Kristeva (2005: 97), "où la physiologie rejoint la symbolisation”. 
Braidotti, Rosi (2002), Metamorphoses: Towards a Materialist Theory of Becoming. Cambridge: Polity Press.

Braidotti, Rosi (2007), Transpositions: On Nomadic Ethics (2006). Cambridge: Polity Press.

Braidotti, Rosi (2005-2006), “Affirming the Affirmative: On Nomadic Affectivity”, Rbizomes, 11/12, Fall/Spring.

Butler, Judith (1990), Gender Trouble: Feminism and the Subversion of Identity. New York: Routledge.

Butler, Judith (1991), "Imitation and gender insubordination”, in Diana Fuss (org.), Inside/Out: Lesbian Theories, Gay Theories. New York: Routledge.

Butler, Judith (1994), Bodies that Matter. On the Discursive Limits of Sex. London: Routledge.

Butler, Judith; Salih, Sara (orgs.) (2004), The Judith Butler Reader. Malden, MA: Blackwell. Cixous, Helène (1992), "Le sexe ou la tête", in Le Langage des femmes, intr. Françoise Collin. Bruxelles: Editions Complexe (publicado originalmente em Les Cabiers du Grif, 13, Outubro 1976, 5-15).

Collins, Patricia Hill (1990), Black Feminist Thought: Knowledge, Consciousness, and the Politics of Empowerment. Boston: Unwyn Hyman.

Collins, Patricia Hill (2000), Black Feminist Thought: Knowledge, Consciousness, and the Politics of Empowerment. $2^{\text {nd }}$ rev. ed. London/New York: Routledge.

Fuss, Diana (org.) (1991), Inside/Out: Lesbian Theories, Gay Theories. New York: Routledge.

Gaard, Greta C. (org.) (1993), Ecofeminism: Women, Animals, Nature. Philadelphia: Temple UP.

Green, Adam Isaiah (2002), "Gay But Not Queer: Toward a Post-Queer Study of Sexuality", Theory and Society, 31(4), 521-545.

Grosz, Elizabeth (org.) (1999), Becomings: Explorations in Time, Memory and Futures. N.Y.: Cornell UP.

Halberstam, Judith; Livingstone, Ira (orgs.) (1995), Posthuman Bodies. Bloomington: Indiana UP.

Haraway, Donna (2004a), “A Manifesto for Cyborgs: Science, Technology, and Socialist Feminism in the 80's”, in The Haraway Reader. New York/London: Routledge.

Haraway, Donna (2004b), "Modest_Witness@Second_Millenium”, in The Haraway Reader. New York /London: Routledge.

Hoagland, Sarah Lucia; Penelope, Julia (orgs.) (1988), For Lesbians Only: A Separatist Anthology. London: Onlywomen Press.

Irigaray, Luce (1992), J'aime à toi. Esquisse d'une félicité dans l'bistoire. Paris: Grasset. Kristeva, Julia (2005), La Haine et le pardon. Pouvoirs et limites de la psychanalyse III. Paris: Fayard.

Kristeva, Julia; Clément, Catherine (1998), Le Féminin et le sacré. Paris: Stock. 
Laurettis, Teresa de (1991), "Queer Theory, Lesbian and Gay Studies: An Introduction”, Differences: A Journal of Feminist Cultural Studies, 3/2, Summer, iii-xviii.

Lilly, Mark (org.) (1990), Lesbian and Gay Writing: An Anthology of Critical Essays. Houndmills, Basingstoke, Hampshire: Macmillan.

Martin, Biddy (1979), "Feminist Metaphysics, a Critique of Mary Daly's Gyn/ecology”, Women's Studies Research Center Working Paper Series, Univ. Wisconsin-Madison, no. 4.

Martin, Biddy (1994), "Sexualities without Genders and Other Queer Utopias", Diacritics, 24(2/3), 104-121.

O'Grady, Kathleen (1996), "Nomadic Philosopher: A Conversation with Rosi Braidotti”, in Women's Education de femmes, 12(1), 35-39.

Parisi, Luciana (2004), Abstract Sex: Philosophy, Bio-technology and the Mutations of Desire. London/New York: Continuum.

Pearson, Keith Ansell (1997), Deleuze and Philosophy: The Difference Engineer. London: Routledge.

Roscoe, Will (org.) (1988), Living the Spirit: A Gay American Indian Anthology. New York: St. Martin's Press.

Salih, Sara (2004), "Introduction”, in S. Salih e J. Butler (org.), The Judith Butler's Reader. Malden, MA: Blackwell.

Showalter, Elaine (1979), "Toward a Feminist Poetics", Women's Writing and Writing about Women. London: Croom Helm.

Sedgwick, Eve Kosofsky (1990), Epistemology of the Closet. Harmondsworth: Penguin. Shiva, Vedanta (1988), Staying Alive: Women, Ecology and Development. London: Zed Books.

Shiva, Vedanta (1997), Biopiracy: The Plunder of Nature and Knowledge. Boston: South End Press.

Stanton, Domna (1980), "Language and Revolution: The French-American Disconnection", in Hester Eisenstein e Alice Jardine (orgs.), The Future of Difference. New Brunswick and London: Rutgers Univ. Press.

Star, Susan Leigh (1991), "Power, Technology and the Phenomenology of Conventions", in John Law (org.), A Sociology of Monsters. London: Routledge.

Tronto, Joan (1989), "Women and Caring: What Can Feminists Learn about Morality from Caring?”, in Alison Jaggar e Susan Bordo (orgs.), Gender/Body/Knowledge. New Brunswick and London: University of Rutgers Press. 